\title{
O ASSISTENTE SOCIAL NA SAÚDE MENTAL: ESPAÇOS DE ATUAÇÃO
}

\section{ARTIGO DE REVISÃo}

ROCHA, Antonia Adriana de Lima ${ }^{1}$

ROCHA, Antonia Adriana de Lima. $\mathrm{O}$ assistente social na saúde mental: espaços de atuação. Revista Científica Multidisciplinar Núcleo do Conhecimento. Ano 06, Ed. 03, Vol. 15, pp. 34-51. Março de 2021. ISSN: 2448-0959, Link de acesso: https://www.nucleodoconhecimento.com.br/saude/espacos-de-atuacao, DOI: 10.32749/nucleodoconhecimento.com.br/saude/espacos-de-atuacao

\section{RESUMO}

O presente trabalho tem por objetivo apresentar um estudo sobre a atuação do assistente social na saúde mental e seus respectivos espaços de atuação. A saúde mental no Brasil tem um histórico de exclusão, assim, a presença de um profissional se faz necessário nesses espaços, pois lidam com esses pacientes, que além da exclusão social, sofrem outros problemas que são próprios da sociedade capitalista, como: miséria, pobreza, preconceitos, entre outros. Os espaços mais comuns de atuação são os Centros de Atenção Psicossocial-CAPS, instituições com objetivo de dar autonomia e cidadania aos usuários. A metodologia utilizada, foi pesquisa bibliográfica, para dar embasamento teórico à pesquisa, que tem uma abordagem qualitativa. Concluiu-se que na saúde mental, a atuação do assistente social é feita por meio de três objetivos, são elas: verificação das demandas trazidas pelas instituições psiquiátricas, acompanhamento das necessidades sociais de cada usuário/paciente e medidas para solucionar problemas como a exclusão desses usuários, por meio a integração à família e a sociedade.

\footnotetext{
${ }^{1}$ Graduada em Serviço Social - Graduanda do Curso de Direito.
}

RC: 81084

Disponível em: https://www.nucleodoconhecimento.com.br/saude/espacos-de- 
Palavras-chave: Espaços de Atuação, Serviço social, Saúde Mental.

\section{INTRODUÇÃO}

O presente trabalho vai apresentar um estudo sobre a atuação do assistente social na saúde mental, e os espaços de atuação nessa área. A saúde mental no Brasil tem um histórico de exclusão de seus pacientes por parte da sociedade, que propaga que as pessoas que não são "ditas normais", não se adequam aos padrões sociais e são excluídas socialmente (PAES, 2017).

Dessa forma, ainda segundo Paes (2017) a presença de um profissional se faz necessário nesses espaços, pois lidam com esses pacientes que além da exclusão social, e dos problemas com os transtornos mentais, ainda sofrem com outras formas de exclusão, que são próprias da sociedade capitalista no qual estão inseridos, como: miséria, pobreza, preconceitos, entre outros.

Os espaços mais comuns de atuação dos assistentes sociais são os Centros de Atenção Psicossocial-CAPS, instituições com objetivo de dar autonomia e cidadania aos usuários. De acordo com Ministério da Saúde (2004) os CAPS podem ser divididos de acordo com o atendimento, podendo ser: CAPSI, CAPSII, CAPSIII, CAPSi e CAPSad.

- O CAPS I faz atendimentos a pacientes com transtornos severos e persistentes, tendo uma média de 9 funcionários, em municípios com 20 a 50 mil habitantes.

- O CAPS II faz atendimento a municípios com maior volume de habitantes se comparado com o CAPSI, tendo o atendimento caracterizado igualmente ao anterior.

- O CAPS III tem uma cobertura maior que os anteriores, o que o caracteriza como maior da rede, sendo capaz de atender municípios com até 200 mil habitantes.

RC: 81084

Disponível em: https://www.nucleodoconhecimento.com.br/saude/espacos-de- 
- O CAPSi é um tipo de centro específico para o atendimento de crianças e adolescentes com transtornos mentais.

- O CAPSad é próprio para pessoas que tem dependência com álcool ou drogas.

De acordo com dados do Ministério da Saúde (2011) no Brasil existiam mais de 761 CAPS I implantados, 418 CAPS II, 55 CAPS III, 128 CAPSi e 258 CAPSad, totalizando 1620 CAPS.

A função desses centros é atender de forma diária as demandas, fazendo os atendimentos individualizados e proporcionando a inclusão social dos usuários. Os mesmos para terem atendimento no CAPS, precisam que um familiar responsável procure o serviço, ou que seja encaminhado pela Estratégia de Saúde da Família (ESF) ou por qualquer outro serviço de saúde (MINISTÉRIO DA SAÚDE, 2004).

Assim, o objetivo do trabalho é apresentar um estudo sobre a atuação do assistente social na saúde mental, e seus respectivos espaços de atuação. Tendo como objetivos específicos: conhecer a psiquiatria no Brasil; compreender o trabalho do assistente social na saúde mental; entender o que é Centro de Atenção Psicossocial - CAPS; apresentar a atuação do assistente social no CAPS, com ênfase no CAPSII.

Para atingir aos objetivos propostos, foi utilizado uma metodologia através de uma pesquisa bibliográfica, que é um levantamento de vários artigos que tratam de determinado assunto, onde se faz a análise e síntese dos mais relevantes, esse modelo de pesquisa serve de instrumento de avaliação e aprofundamento de pesquisas publicadas (FONSECA, 2002). O estudo foi realizado através de uma abordagem qualitativa, que de acordo com Silveira e Córdova (2009, p. 31), "não se preocupa com representatividade numérica, mas sim, com o aprofundamento da compreensão de um grupo social, de uma organização, etc".

RC: 81084

Disponível em: https://www.nucleodoconhecimento.com.br/saude/espacos-de- 


\section{A QUESTÃO PSIQUIÁTRICA NO BRASIL AO LONGO DA HISTÓRIA}

A história da psiquiatria pode ser datada desde o período colonial, onde o tratamento psiquiátrico era realmente precário. Grande parte dos tratamentos, ou melhor, cuidados psiquiátricos, eram prestados por pessoas sem qualificação específica, ou seja, curandeiros, sacerdotes católicos. Nesse momento da história, os médicos eram raríssimos, e os poucos encontrados serviam as pessoas com maior poder aquisitivo (MIRANDA-SÁ JR., 2007).

Até o século $\mathrm{XVIII}$, o conceito de hospitais era diferente do que temos atualmente, muitas dessas instituições eram confundidas com albergues, onde pessoas doentes eram aglomeradas sem os cuidados de um tutor. Nessa época, as Irmandades das Santas Casas de Misericórdia acolhiam e albergavam esses doentes em condições sanitárias muito más (MIRANDA-SÁ JR., 2007).

Um marco para assistência psiquiátrica no Brasil foi a criação do Hospital Psiquiátrico Pedro II, que é datado em 1852, que foi inicialmente construída no Rio de Janeiro, e em consequência desse, outros mais foram sendo inaugurados em São Paulo, Pernambuco, Bahia e Minas Gerais. Esses hospitais tinha um discurso baseado no modelo Europeu, onde tinha a exclusão como finalidade (MINAS GERAIS, 2006).

Segundo o Dr. Jacinto dos Santos (2012), as pessoas com distúrbios mentais "alienados mentais" nas palavras do Dr. Recebiam na verdade um tratamento moral e não científico, tais tratamentos se baseavam em castigos, espaçamentos e reclusão total, não era um tratamento.

Os castigos que eram denominados de tratamentos eram feitos por médicos alienistas, pois inexistia psiquiatras nessa época.

$\mathrm{RC}: 81084$

Disponível em: https://www.nucleodoconhecimento.com.br/saude/espacos-de- 
Em 1950 os hospícios estavam em situação deplorável, apresentando problemas como: superlotação; deficiência de pessoal; maus-tratos; péssimas condições físicas; cuidados técnicos escassos e automatizados (MINAS GERAIS, 2006).

Nos anos de 1970 as comunidades terapêuticas que vieram substituir o modelo dos hospitais especializados, ou seja, teve-se o início de experiências de transformação da assistência, pautadas, no começo, pela reforma intramuros das instituições psiquiátricas (KNOPP, 2012).

Nesse mesmo ano se deu início a Reforma Psiquiátrica no Brasil, que teve como finalidade a melhora qualitativa dos serviços prestados, tendo início devido à precariedade dos serviços prestados até então, que teve sua motivação na crise do modelo de assistência centrado nos hospitais psiquiátricos e pelas lutas dos movimentos sociais, em defesa dos direitos dos pacientes com transtornos mentais (KNOPP, 2012).

De acordo com Knopp (2012) no Brasil, essas mudanças trazidas pela Reforma Psiquiátrica vieram no ano de 1978, que teve como estopim as lutas dos movimentos sociais em favor dos pacientes psiquiátricos. Nessa época surgiu o Movimento dos Trabalhadores em Saúde Mental - MTSM, que era formado por pessoas que tinha um complexo histórico de internações psiquiátricas associações de familiares de portadores de transtorno mental, trabalhadores participantes do Movimento Sanitário, membros de associações profissionais, entre outros. O surgimento de tal movimento foi iniciado devido os maus tratos que ocorriam nos manicômios, os tratamentos sub-humanos e a falta de humanização.

No ano de 1987 aconteceu a 1ํㅡㄹerência Nacional de Saúde Mental, que discutiu sobre a relação entre cidadania e doença mental. Em 1992 aconteceu a $2^{\circ}$ Conferência Nacional de Saúde Mental, dessa vez trazendo as críticas ao modelo assistencial. E em 2001 aconteceu a 3ํㅡㄹ Conferência Nacional de Saúde Mental,

RC: 81084

Disponível em: https://www.nucleodoconhecimento.com.br/saude/espacos-de- 
voltando a discussão trazida pela $1^{\circ}$ Conferência que foi a discussão da cidadania e a doença mental (MEDEIROS, 2003).

Assim, a proposta da Reforma é a inclusão dessas pessoas novamente na sociedade, deixando de lado o tratamento em série, ou seja, no qual todos eram tratados da mesma forma, pois com os avanços da tecnologia se entendeu que cada um deve ser tratado de acordo com sua patologia, não sendo possível assim tratar todos com o mesmo remédio ou mesmo tratamento.

Dessa forma, entende-se que os desafios para a construção da saúde mental no Brasil ocorreu, como já mencionado, através da Reforma Psiquiátrica, que defendia as mudanças nos modelos de tratamento e práticas em saúde mental. O objetivo da reforma era a modificação da internação como única forma de tratamento dos doentes, e dessa forma foi sendo introduzida a terapêutica na rede dos serviços territoriais de atenção psicossocial (MINISTÉRIO DA SAÚDE, 2005).

Contudo, a reforma não foi uma tarefa fácil, e exigiu uma participação assídua dos trabalhadores da rede de saúde mental. De acordo com Silva (2008) a inclusão das redes de atenção à saúde mental, pode e deve oferecer uma atenção de forma integral aos doentes e suas famílias, na busca por sanar as múltiplas necessidades de ambos, através de ações sequenciadas e articuladas para possibilitar o cuidado integral ao portador de transtorno mental.

Assim, se entende que a reforma psiquiátrica foi uma mudança muito além da estrutura dos serviços até então prestados, devido à reforma foi desenvolvida uma Comissão de Saúde - CSM, que tinha como objetivo dar uma contribuição para efetivar a Reforma Psiquiátrica em âmbito municipal, pois sua origem se deu no Estado do Rio Grande do Sul/Brasil. Eram feitas reuniões, com espaço de tempo semanal, onde participavam trabalhadores dos serviços de saúde mental e de outros serviços de atenção à saúde do município, docentes e discentes de cursos da saúde (AMARANTE, 2007).

$\mathrm{RC}: 81084$

Disponível em: https://www.nucleodoconhecimento.com.br/saude/espacos-de- 
Ainda segundo Amarante (2007) após a criação da CSM, e das constantes reuniões, foi se percebendo a necessidade de uma rede de atenção em saúde mental, para que servisse como facilitador no atendimento de pessoas com transtornos mentais, contudo a construção de tal rede é uma tarefa árdua, devido sua complexidade, sendo necessário cooperação e iniciativa e vários atores sociais.

Um aspecto fundamental para a consolidação da Reforma Psiquiátrica foi o Sistema Único de Saúde, que inclui a atenção à saúde mental como de base comunitária, tendo movimentos em direção à busca da emancipação das pessoas com transtornos mentais (MELLO, 2007).

Esse avanço se deu por meio da Constituição Federal de 1988, na qual as Políticas sociais são trazidas no art. 6ำ que pontua cada direito social cabível à políticas, dentre eles: saúde, educação, moradia, trabalho, lazer, maternidade entre outros.

A saúde é ainda destacada no art. 196 da mesma constituição, assim, a saúde mental juntamente com o SUS segue as conformidades do art. 196, que são: diretrizes de descentralização, atendimento integral, com prioridade às atividades preventivas, sem prejuízo dos serviços assistenciais, e com participação da comunidade (FUREGATO, 2009).

De acordo com Furegato (2009) para conseguir seguir as normativas trazidas pela $\mathrm{CF} / 88$, foi necessária a criação de leis, portarias e normativas específicas e detalhadas sobre cada um dos serviços que passaram a compor a rede de atenção em saúde mental para internação, semi-internação, acompanhamento, urgências e emergências, ressocialização, promoção da saúde, da cidadania e inserção social.

Algumas dessas leis foram: Leis Federais $8080 / 1990$ e 8142/90. As Leis, 32 Portarias e Resoluções do Ministério da Saúde priorizam o atendimento ao portador de transtorno mental em sistema comunitário (KNOPP, 2012).

RC: 81084

Disponível em: https://www.nucleodoconhecimento.com.br/saude/espacos-de- 
Em 1992 é promulgada a Lei Estadual no 9716, que trata sobre a Reforma Psiquiátrica e contém as regulamentações: "Art. 3: fica vedada a construção e ampliação de hospitais psiquiátricos, públicos ou privados e a contratação e financiamento, pelo setor público, de novos leitos nesses hospitais". Assim, com essa nova lei, preenche a lacuna deixada pela Lei 10.216/2001 (GASTAL et al., 2007).

A Lei no 10.216/2001 que transforma a atenção em Saúde Mental, dando prioridade ao atendimento e oferecimento de tratamento em serviços de base comunitária, trata ainda dos direitos e proteção das pessoas com transtornos mentais, mas não institui mecanismos claros para a progressiva extinção dos manicômios. Sendo essa uma das lacunas deixadas pela lei, contudo a mesma traz um novo ritmo ao processo de Reforma Sanitária (BRASIL, 2005).

Outras normativas segundo o Ministério da Saúde (2005) é os CAPS - Centros de Atenção Psicossocial, os SRTs - Serviços Residenciais Terapêuticos e as UPHG Unidades Psiquiátricas em Hospitais Gerais, todo incluídos pelo SUS, que ainda pretende incluir outras ações como: Saúde Mental na atenção básica.

Dessa forma, de acordo com Knopp (2012) a política de Saúde Mental tem por objetivo proporcionar o tratamento digno e de qualidade ao portador de doença mental, de forma contínua para todos os hospitais psiquiátricos por meio do Programa Nacional de Avaliação dos Serviços Hospitalares - PNASH/Psiquiatria.

\section{CENTRO DE ATENÇÃO PSICOSSOCIAL - CAPS}

Os CAPS - Centros de Atenção Psicossocial, foram criados como uma estratégia da Reforma Psiquiátrica Brasileira, pois esses centros foram criados para substituir os hospitais psiquiátricos que prestavam esse atendimento em todo o país.

Os CAPS têm emergido como a principal estratégia para transformação do modelo asilar de assistência à saúde mental e para

$\mathrm{RC}: 81084$

Disponível em: https://www.nucleodoconhecimento.com.br/saude/espacos-de- 
a garantia de direitos aos usuários, já que tem se constituído na rede como serviço que se diferencia das estruturas tradicionais e que se orienta pela ampliação do espaço de participação social do sujeito que sofre, pela democratização das ações, pela não segregação do adoecimento psíquico e pela valorização da subjetividade, com base das ações multiprofissionais (TAVARES; SOUSA, 2009, p.254).

A diferença dos CAPS é que são instituições que fazem atendimentos municipais, para uma cobertura mais descentralizada, tendo como funções básicas, de acordo com Leal e Antoni (2013):

- Atendimento diário e continuado nos casos necessários;

- Atender indivíduos que apresentam transtornos mentais;

- Solucionar problemas que circundam os pacientes, tais como: sociais, políticos e econômico;

- Organizar a atenção psicossocial nos municípios;

- Proporcionar reinserção social aos pacientes, por meio do acesso ao trabalho, atividades de lazer, entre outros.

O que motiva a instalação de um CAPS em um determinado município é o perfil populacional, que possibilita o planejamento e implantação dos centros. Leal e Antoni (2013), dizem ainda que os CAPS se caracterizam por serviços comunitários, regionais e ambulatoriais, que articulam serviços da saúde coletiva e da saúde mental.

Como já mencionado, os CAPS se subdividem, podendo ser segundo Brasil (2002), em CAPS I, CAPS II e CAPS III, os quais são classificados por seu porte de atendimento e serviços que são prestados no território que estão inseridos; os CAPS Infantil -CAPSi e os CAPS Álcool e Drogas - CAPSad, esses são destinados ao atendimento específico de crianças e adolescentes que passam a ter transtornos mentais devido ao uso de drogas e outras substâncias psicoativas.

$\mathrm{RC}: 81084$

Disponível em: https://www.nucleodoconhecimento.com.br/saude/espacos-de- 


\section{ATUAÇÃO DO ASSISTENTE SOCIAL NA SAÚDE MENTAL}

O espaço de trabalho na saúde mental foi criado para o serviço social a partir da reforma psiquiátrica, pois a mesma teve uma formação social e política, o que consequentemente necessitava de profissionais que atuassem nessas áreas. Essa interação da profissão com a saúde mental trouxe avanços para o tratamento dos pacientes, e foi por meio do serviço social que em 1990 se iniciava a criação de projetos de intervenção, como: atenção domiciliar, projetos de trabalho e moradia e atenção psicossocial (COUTINHO; SANTOS, 2016).

De acordo com Soares (2006), o assistente social ganhou espaço na área de saúde mental devido seu trabalho diferenciado, que atua diretamente com familiares, através de trabalhos em grupo, atendimento a domicílio, entre outros, que deram ao profissional privilégios no setor, por ser capaz de dar respostas relacionadas as questões sociais envolvidas por trás dos transtornos mentais, porém sem perder o foco nas dimensões biológica e psíquica.

Soares (2006, p. 36) diz em suas palavras que "As atividades realizadas por esse profissional permitem que ele possa detectar questões importantes para o processo de reabilitação, questões estas que podem estar ligadas à família, ao meio social na qual vive ou ao próprio transtorno mental".

Assim, Bandeira (2014), completa o que foi dito por Soares (2006), referente ao trabalho do assistente social na saúde mental, dizendo que os profissionais durante sua atuação, necessitam compreender a dimensão dos usuários e suas complexidades, para atuar de forma consciente e crítica.

Para ter conhecimento sobre a complexidade dos usuários, da saúde mental, CFSS (2010), diz que o assistente social deve ser capaz de identificar a realidade do usuário, onde ele está socialmente inserido, para assim saber buscar as formas de melhor intervenção.

RC: 81084

Disponível em: https://www.nucleodoconhecimento.com.br/saude/espacos-de- 
Assim, o assistente social tem como objetivos de trabalho dentro das instituições de saúde mental de acordo com Bisneto (2007), o atendimento social a população usuária dessas instituições, que trazem questões que são próprias do assistente social, como por exemplo: relações familiares, a pobreza em que muitos vivem, a exclusão social, entre outras. Dessa forma, o segundo objetivo é referente a inserir esses pacientes novamente na sociedade ou no âmbito familiar, e para que isso seja possível, de acordo com o autor, é fundamental que o profissional esteja preparado para as adversidades que podem surgir, fazendo isso por meio de uma especialização e estudos dos processos psicossociais integrados aos objetivos do serviço social.

Por fim, temos o último objetivo do profissional que trata sobre as demandas trazidas pelas instituições psiquiátricas, ou seja, o assistente social faz uma triagem nos pacientes, identificando aqueles que realmente necessitam do tratamento em instituições de saúde mental, caso seja verificado que não, esses pacientes são encaminhados para os devidos atendimentos aos quais se adequam (BISNETO, 2007).

Contudo é importante salientar, que o assistente social não é um profissional de saúde, embora tenha atribuições para atuar nas unidades, o que os diferencia de acordo com o Código de Ética do Assistente Social (1993), é que o assistente social é um profissional que visualiza e apresenta o paciente/usuário como um indivíduo detentor de direitos, que estão garantidos pela Constituição federal de 1988, ou seja, os assistentes sociais são os únicos profissionais que buscam a defesa dos direitos dos usuários, com tratamento humanista e garantia de igualdade, bem como está previsto constitucionalmente.

$\mathrm{Na}$ Constituição Federal de 1988, esses direitos estão preconizados nos arts. $1^{\circ}$, $3^{\circ}$ e 5o, que apresentam os seguintes textos:

RC: 81084

Disponível em: https://www.nucleodoconhecimento.com.br/saude/espacos-de- 
Art. 1ํ A República Federativa do Brasil, formada pela união indissolúvel dos Estados e Municípios e do Distrito Federal, constituise em Estado Democrático de Direito e tem como fundamentos:

I - a soberania;

II - a cidadania;

III - a dignidade da pessoa humana;

$[\ldots]$

Art. 3ำ Constituem objetivos fundamentais da República Federativa do Brasil:

I - construir uma sociedade livre, justa e solidária;

II - garantir o desenvolvimento nacional;

III - erradicar a pobreza e a marginalização e reduzir as desigualdades sociais e

regionais;

IV - promover o bem de todos, sem preconceitos de origem, raça, sexo, cor, idade e

quaisquer outras formas de discriminação.

$[\ldots]$

Art. 5 Todos são iguais perante a lei, sem distinção de qualquer natureza, garantindo-se aos brasileiros e aos estrangeiros residentes no País a inviolabilidade do direito à vida, à liberdade, à igualdade, à segurança e à propriedade (BRASIL, 2017, p. 17).

Os artigos constitucionais supracitados, são apenas alguns dos que trazem os diretos dos cidadãos, aos quais os assistentes sociais são formados para garantir aos seus usuários, em qualquer área que esteja atuando.

Um dos espaços de atuação do assistente social dentro da saúde mental são os CAPS, já mencionado anteriormente. De uma forma mais específica, trataremos nesse trabalho sobre o a atuação no CAPS II. Os CAPS II's estão ligados a um

RC: 81084

Disponível em: https://www.nucleodoconhecimento.com.br/saude/espacos-de- 
programa criado no SUS (Sistema Único de Saúde) e estão destinados ao atendimento de grupos, visitas domiciliares para atendimento a família, e trabalhos voltados a reinserção social de acordo com a demanda apresentada, objetivando a melhoria da qualidade de vida do pessoal com doença mental ou química (MARTINHAGO; OLIVEIRA, 2012).

Os CAPS II's e tem como objetivo principal, de acordo com Martinhago e Oliveira (2012):

- Intervir junto ao usuário a viabilização dos direitos sociais;

- Identificar as expressões da questão social relacionadas ao uso abusivo de substâncias psicoativas;

- Promover o direito a reinserção na família/sociedade, ofertar ações que capacite o indivíduo ao mercado de trabalho (oficina profissionalizantes).

Este deve pelo menos conter em sua equipe técnica, tais como: psicólogo, assistente social, pedagogo e educador social.

O Público-alvo dos CAPS II's são adultos e adolescentes com transtornos mentais persistentes. Essas demandas chegam através de encaminhamentos, do Ministério Público, UBSs ou da sociedade. Os serviços ofertados devem ser desdobrados de modo a ser planejado junto com a rede de serviços da assistência social, órgão de defesa de direitos das demais políticas públicas.

O planejamento assistencial é primordial para fortalecer as possibilidades de inclusão do indivíduo em uma organização de proteção, que possa contribuir para reconstrução de vida mais digna (PREFEITURA DE EMBU, 2019).

A atuação do assistente social na saúde de acordo com o CFESS (2010) é nas mais diversas expressões da questão social, que podem envolver o preconceito, estigma e vulnerabilidade em que as pessoas com transtorno mental, usuárias do serviço

RC: 81084

Disponível em: https://www.nucleodoconhecimento.com.br/saude/espacos-de- 
vivenciam. Frente a essa demanda, o assistente social foi inserido na equipe multiprofissional dos CAPS, após a Reforma Psiquiátrica e do reconhecimento da saúde como direito pela Constituição Federal de 1988.

Dessa forma, dentro dos CAPS II, a atuação do assistente social varia de acordo com a demanda, que pode ser uma simples assistência psiquiátrica, e também as relações que envolvem os usuários, suas famílias, as relações sociais, bem como econômica e culturais (SILVA et al, 2015).

O objetivo do trabalho do assistente social com os usuários do CAPS II é de acordo com o CFESS (2010) promover uma melhor qualidade de vida aos usuários, de forma que facilite a vida dos mesmos e que os prejuízos causados pelos transtornos sejam amenizados, tanto no âmbito biológico quanto psicológico e social.

Entre muitas funções do assistente social dentro dos CAPS II, uma que vale ser destacada de acordo com Silva et al (2015), é o uso de instrumentos de avaliação da prática, que é feita utilizando um mapa de produção, no qual o assistente social sintetiza todas as ações realizadas por ele em cada mês, fazendo o detalhamento do dia e a quantidade de usuários que participam dos encontros grupais. Esse mapa de produção é entregue geralmente aos gestores como uma forma de controle.

É possível concluir por meio dos referenciais apresentados, que o assistente social foi inserido na atuação da política de saúde mental, por ser um profissional qualificado a lidar com as questões sociais, políticas e econômicas que são trazidas pelos pacientes, e que influenciam no tratamento e na vida deles.

\section{ANÁLISE DOS RESULTADOS}

Por meio das pesquisas realizadas, foi possível compreender que o assistente social foi inserido na área da saúde mental, devido uma necessidade de profissionais que atuassem com questões sociais e políticas trazidas pelos pacientes. Nessa ótica,

RC: 81084

Disponível em: https://www.nucleodoconhecimento.com.br/saude/espacos-de- 
observou-se que a saúde mental no Brasil é muito mais que uma questão de saúde, ela traz problemas complexos que se desenvolvem devido as características das sociedades capitalistas, como por exemplo: preconceitos, exclusão social, etc.

Foi possível ainda entender os objetivos de trabalho do assistente social na saúde mental, como foi apresentado por Bisneto (2007), são basicamente três: a necessidade do profissional da área no atendimento a esses pacientes; integração dos pacientes à sociedade e dentro da própria família, pois em muitos casos são excluídos até do ambiente familiar devido a preconceitos e outras questões, geralmente financeiras; e uma crescente demanda trazida por parte dos estabelecimentos psiquiátricos, demanda essas que apresentam questões muito além do que o problema de saúde mental.

Outro ponto relevante na pesquisa, é sobre os espaços de trabalho do assistente social nessa área de atuação, no qual foi apresentado o CAPS, que como já mencionado, são Centros de Atenção Psicossocial, que tem por objetivo como bem ressaltou Leal e Antoni (2013), substituir os hospitais psiquiátricos, dando um atendimento diários e contínuos às comunidades, e são localizados nos municípios e são abertos a todos que dele necessitar.

Para melhor atender a comunidade, os CAPS se subdividem de acordo com a necessidade e o porte de cada município, sendo subdividido em: CAPS I, CAPS II, CAPS III, CAPS i e CAPS ad, segundo o Ministério da Saúde (2004).

Dentre as subdivisões do CAPS, o trabalho deu ênfase ao CAPSII, que faz atendimentos de acordo com o citado por Paes (2017) a pacientes com transtornos mentais severos e persistentes, e atendem a municípios com mais de 50 mil habitantes, sendo uma demanda significativa para o assistente social, e por essa razão foi dado ênfase a essa subdivisão do CAPS.

RC: 81084

Disponível em: https://www.nucleodoconhecimento.com.br/saude/espacos-de- 
Assim, ficou explícito que o CAPS II tem por objetivo atender as demandas apresentadas pela população em suas necessidades, usando o direito a ela atribuída mediando a dispersão da mediação e o trabalho psicoterapêutico, na modalidade do tratamento semi-interventivo.

A atuação do assistente social com bem pontuou Silva et al (2015) é feita por meio de projetos terapêuticos singulares, de forma individual e em grupos de reflexão, sendo fundamental conhecer o histórico do paciente através da triagem, que pode ser considerado um acolhimento inicial. Após essa triagem, é feito grupos de orientações sociais ao usuário, familiares e/ou cuidador, no qual ainda podem ser feitas visitas domiciliares e institucionais e articulação intersetorial com a RAPS Rede de Atenção Psicossocial e Rede Socioassistencial com os devidos encaminhamentos.

Dessa forma, foi possível compreender que o trabalho do assistente social dentro dos CAPS II, vai depender da demanda institucional, podendo ser uma simples assistência, com questões que envolvem os pacientes e seus familiares, e outras questões mais complexas, como problemas econômicos e culturais aos quais os pacientes estão inseridos.

\section{CONCLUSÕES}

Evidencia-se que a inserção do assistente social na saúde mental foi resultado dos avanços trazidos pela Reforma Psiquiátrica, que possibilitou grandes melhorias no âmbito da saúde mental, como o reconhecimento da importância da reinserção social, pois passou a verificar que a demanda social era crescente e necessitava de um profissional capacitado para atuar com essas questões trazidas pelos pacientes.

Na saúde mental, a atuação do assistente social é feita por meio de três objetivos: verificação das demandas trazidas pelas instituições psiquiátricas; acompanhamento das necessidades sociais de cada usuário/paciente; e medidas para solucionar

$\mathrm{RC}: 81084$

Disponível em: https://www.nucleodoconhecimento.com.br/saude/espacos-de- 
problemas como a exclusão desses usuários, por meio a integração a família e a sociedade. Em suma, o profissional tem como um de seus objetivos principais a promoção da qualidade de vida dos usuários, por meio da minoração das consequências trazidas pelos transtornos que os mesmos carregam, tanto no âmbito biológico quanto psicológico e social.

Um dos espaços de atuação dos assistentes sociais na saúde mental, são os Centros de Atenção Psicossocial - CAPS, os quais se subdividem, de acordo com o porte e atendimentos que são ofertados por cada um. No CAPSII, como foi apresentado na pesquisa, a atuação do assistente social é feita por meio do atendimento das demandas que são apresentadas pela população do município ao qual o centro está localizado, realizando com essas demandas projetos terapêuticos singulares, de forma individual e em grupos de reflexão.

\section{REFERÊNCIAS}

AMARANTE, PD. Saúde mental e atenção psicossocial. Temas em saúde. Rio de Janeiro: Fiocruz; 2007.

BANDEIRA, Gabrieli de Souza. O trabalho do assistente social na política de atenção aos usuários de drogas. 2014. 114 fls. Dissertação (mestrado em Serviço Social). Faculdade de Serviço Social - PUCRS. Porto Alegre. 2014. Disponível em: repositorio.pucrs.br/dspace/.../1/000455736-Texto\%2BCompleto-0.pdf. Acesso em: 27 abr. 2019.

BISNETO, José Augusto. Serviço social e saúde mental: uma análise institucional da prática. São Paulo: Cortez, 2007.

BRASIL. Ministério da Saúde. Secretaria de Atenção à Saúde. DAPE. Coordenação Geral de Saúde Mental. Reforma psiquiátrica e política de saúde mental no Brasil. Documento apresentado à Conferência Regional de Reforma dos

RC: 81084

Disponível em: https://www.nucleodoconhecimento.com.br/saude/espacos-de- 
Serviços de Saúde Mental: 15 anos depois de Caracas. OPAS. Brasília, novembro de 2005.

BRASIL. Constituição (1988). Constituição da República Federativa do Brasil [recurso eletrônico]. -- Brasília: Supremo Tribunal Federal, Secretaria de Documentação, 2017.

BRASIL. Código de ética do/a assistente social. Lei 8.662/93 de regulamentação da profissão. - 10a . ed. rev. e atual. - Brasília: Conselho Federal de Serviço Social, 2012. Disponível em: http://www.cfess.org.br/arquivos/CEP_CFESS-SITE.pdf. Acesso em: 28 abr. 2019.

BRASIL. Ministério da Saúde. Portaria n. 336/GM de 19 de fevereiro de 2002. Disponível em http://portal.saude.gov.br/portal/arquivos/pdf/Portaria\%20GM\%203362002.pdf. Acesso em: 28 abr. 2019.

COUTINHO, Dalsiza Cláudia Macedo Coutinho; SANTOS, Rosemeire dos Santos. O trabalho do/a assistente social na saúde mental Atribuições privativas e competências profissionais em debate. Revista EDUC-Faculdade de Duque de Caxias/Vol. 03- № 1/Jan-Jun 2016. Disponível em: http://uniesp.edu.br/sites/_biblioteca/revistas/20170608151751.pdf. Acesso em: 27 abr. 2019.

CONSELHO FEDERAL DE SERVIÇO SOCIAL (CFESS). Parâmetros para atuação de assistentes sociais na saúde. Brasília, 2010.

FONSECA, J. J. S. Metodologia da pesquisa científica. Fortaleza: UEC, 2002. Apostila.

FUREGATO, Antonia Regina Ferreira. Política de Saúde Mental do Brasil. Rev. esc. enferm. USP vol.43 no.2 São Paulo June, 2009. Disponível em:

RC: 81084

Disponível em: https://www.nucleodoconhecimento.com.br/saude/espacos-de- 
http://www.scielo.br/scielo.php?script=sci_arttext\&pid=S0080-62342009000200001. Acesso em: 26 abr. 2019.

GASTAL, F.L.; LEITE, S.O.; FERNANDES, F.N.; BORBA, A.T. de; KITAMURA, C.M.; BINZ, M.A.R.; AMARAL, M.T. do. Reforma psiquiátrica no Rio Grande do Sul: uma análise histórica, econômica $r$ do impacto da legislação de 1992. Revista de Psiquiatria. Rio Grande do Sul. V.29, n.1, Porto Alegre. Jan/Apr. 2007.

LEAL, Bruna Molina; ANTONI, Clarissa de. Os Centros de Atenção Psicossocial (CAPS): estruturação, interdisciplinaridade e intersetorialidade. Versão impressa ISSN 1413-0394, Aletheia n. 40 Canoas, 2013. Disponível em: http://pepsic.bvsalud.org/scielo.php?script=sci_arttext\&pid=S141303942013000100008. Acesso em: 28 abr. 2019.

KNOPP, Amanda Martins. Saúde Mental, Reforma Psiquiátrica e os CAPS Centros de atenção psicossocial: a atuação do Serviço Social. Trabalho de Conclusão de Curso, apresentado ao Departamento de Serviço Social do Centro Sócio-Econômico da Universidade Federal de Santa Catarina, Florianópolis, 2012. Disponível em: https://repositorio.ufsc.br/bitstream/handle/123456789/103466/TCC\%20AMANDA\%2 OKNOPP.pdf?sequence=1. Acesso em: 24 abr. 2019.

MARTINHAGO, Fernanda; OLIVEIRA, Walter Ferreira de. A prática profissional nos Centros de Atenção Psicossocial II (CAPS II), na perspectiva dos profissionais de saúde mental de Santa Catarina. Saúde em Debate - Rio de Janeiro, v. 36, n. 95, p. 583-594, out./dez. 2012. Disponível em: http://www.scielo.br/pdf/sdeb/v36n95/a10v36n95.pdf. Acesso em: 25 abr. 2019.

MEDEIROS, Andrea dos Santos Silva. Prisão perpétua no Brasil (?): A situação do louco infrator. Periódico de Trabajo Social y Ciencias Sociales. Ed. 29, outoño, 2003.

RC: 81084

Disponível em: https://www.nucleodoconhecimento.com.br/saude/espacos-de- 
MIRANDA-SÁ JR, Luiz Salvador de. Breve histórico da psiquiatria no Brasil: do período colonial à atualidade. Rev Psiquiatr RS. 2007;29(2):156-158. Disponível em: http://www.scielo.br/pdf/rprs/v29n2/v29n2a05.pdf. Acesso em: 26 abr. 2019.

MINAS GERAIS. Secretaria de Estado de Saúde. Linha Guia da Saúde Mental. Belo Horizonte, 2006.

MINISTÉRIO DA SAÚDE. Secretaria de Atenção à Saúde. DAPE, Coordenação Geral de Saúde Mental, Álcool e Outras Drogas. Saúde mental no SUS: os centros de atenção psicossocial. Secretária de Atenção à Saúde. Ministério da Saúde: Brasília. 2004.

MINISTÉRIO DA SAÚDE. Reforma psiquiátrica e política de saúde mental no Brasil. Secretaria de Atenção à Saúde. DAPE. Coordenação Geral de Saúde Mental. Documento apresentado à Conferência Regional de Reforma dos Serviços de Saúde Mental: 15 anos depois de Caracas. OPAS. Brasília; 2005. Disponível: http://bvsms.saude.gov.br/ bvs/publicacoes/Relatorio15_anos_Caracas.pdf. Acesso em: 26 abr. 2019.

MINISTÉRIO DA SAÚDE. Secretaria de Atenção à Saúde. DAPE, Coordenação Geral de Saúde Mental, Álcool e Outras Drogas. Saúde mental no SUS: as novas fronteiras da reforma psiquiátrica. Relatório de Gestão 2007- 2010. Ministério da Saúde: Brasília. 2011.

MELLO, MF; MELLO, AAF; KOHN, R. Epidemiologia da saúde mental no Brasil. Porto Alegre: Artmed; 2007.

PAES, Juliana Santos. Serviço Social e Saúde Mental: desafios e possibilidades para o Assistente Social na política de Saúde Mental. VIII Internacional de Políticas Públicas. 2017. Disponível em: http://www.joinpp.ufma.br/jornadas/joinpp2017/pdfs/eixo14/servicosocialesaudement

$\mathrm{RC}: 81084$

Disponível em: https://www.nucleodoconhecimento.com.br/saude/espacos-de- 
aldesafiosepossibilidadesparaoassistentesocialnapoliticadesau.pdf. Acesso em: 23 abr. 2019.

Prefeitura de Embu. CAPS II Adulto - Centro de Atenção Psicossocial II. Disponível em: http://cidadeembudasartes.sp.gov.br/embu/portal/secretaria/ver/160. Acesso em: 23 abr. 2019.

SANTOS, Jacinto dos. Reforma Psiquiátrica no Brasil. 2012. Disponível em http://www.alternativamedicina.com/historia-da-psiquiatria/reformas-saudemental.html. Acesso em: 22 abr. 2019.

SILVA, SF. Redes de atenção á saúde no SUS: o pacto pela saúde e redes regionalizadas de ações de serviços de saúde. Campinas, SP: IDISA: CONASEMS; 2008. Disponível: http://observasaude.fundap.sp.gov. br/pacto/Redesatencao/Paginas/Default.aspx. Acesso em: 26 abr. 2019.

SILVA, Jackeline Araujo; Et al. O trabalho do assistente social na saúde mental: um olhar a partir da experiência de estágio no CAPS II leste em Teresina-Piauí. VII Jornada Internacional de Políticas Públicas. 2015. Disponível em: http://www.joinpp.ufma.br/jornadas/joinpp2015/pdfs/eixo10/o-trabalho-do-assistentesocial-na-saude-mental-experiencia-de-estagio-no-caps-ii-leste-em-teresina.pdf. Acesso em: 25 abr. 2019.

SILVEIRA, D. T; CÓRDOVA, F. P. A pesquisa cientifica. In: Métodos de pesquisa / [organizado por] Tatiana Engel Gerhardt e Denise Tolfo Silveira ; coordenado pela Universidade Aberta do Brasil - UAB/UFRGS e pelo Curso de Graduação Tecnológica - Planejamento e Gestão para o Desenvolvimento Rural da SEAD/UFRGS. - Porto Alegre: Editora da UFRGS, 2009. p. 31-42.

SOARES, Adriana Oliveira. Serviço Social e saúde mental: a formação de uma prática ou uma prática em formação? Dissertação (Mestrado em Serviço Social)

$\mathrm{RC}: 81084$

Disponível em: https://www.nucleodoconhecimento.com.br/saude/espacos-de- 
Pontifícia Universidade Católica do Rio de Janeiro. Rio de Janeiro, 2006. Disponível em: https://www.maxwell.vrac.puc-rio.br/9543/9543_1.PDF. Acesso em: 27 abr. 2019.

TAVARES, R. C; SOUSA, S. M. G. Os Centros de Atenção Psicossocial e as possibilidades de inovação das práticas em saúde mental. Saúde em Debate, 2009. Disponível em: https://www.redalyc.org/articulo.oa?id=406341771008. Acesso em: 28 abr. 2019.

Enviado: Junho, 2020.

Aprovado: Março, 2020.

RC: 81084

Disponível em: https://www.nucleodoconhecimento.com.br/saude/espacos-de- 